\title{
The effect of footwear on sensory testing in leprosy
}

\author{
C. J. STRATFORD \& B. M. OWEN \\ The Medical School, The University of Newcastle, Newcastle upon \\ Tyne NE2 $4 \mathrm{HH}$
}

Accepted for publication 12 August 1993

\begin{abstract}
Summary The aim of this study was to identify the effect of footwear on sensory testing in leprosy. This was achieved by using 3 methods of sensory testing within 1 district of East Africa. We included 72 leprosy patients and 36 controls (nonleprosy patients) in the study and these were subdivided into 2 groups, depending on whether they normally wore shoes or went barefoot. The methods used were the WHO sensory test, graded monofilaments and the biothesiometer. The results showed significant differences in the threshold levels between both groups of patients with the biothesiometer and monofilaments, demonstrating the importance of having separate values when screening for leprosy and assessing which patients are at the most risk of developing ulcers. The importance of having quantitative methods of testing was also demonstrated, as only then can the results be sufficiently standardized to identify the at-risk groups and also be sufficiently sensitive to differentiate between shoe wearing and nonshoe wearing patients.
\end{abstract}

\section{Introduction}

Plantar ulceration is the most common serious disability in leprosy, ${ }^{1}$ and therefore is of temendous economic importance. This is usually caused by a 'previous ulcer', and the prevention of this first ulcer must be a priority in any leprosy programme. Injuries sustained by the misuse of anaesthetic limbs may cause or lead to ulceration. This can be avoided by educating patients in the care of anaesthetic parts and by protecting the anaesthetic feet with shoes. However, the patient must first recognize and acknowledge their lack of normal sensation and unfortunately many patients are unwilling to admit to being abnormal. Therefore a great deal of interest, concern and time on the part of the medical worker, combined with the ability to define a high risk group quickly and accurately, is needed in order to best use the limited resources available.

The sensory testing of nerve damage has been demonstrated to be a much more reproducible and therefore a more reliable method in comparison to voluntary muscle 
testing. ${ }^{2}$ Several studies demonstrate a relationship between sensory loss and the risk of plantar ulceration. ${ }^{3}$ It is agreed that loss of light touch is not really a disability, but if a patient cannot localize a firm touch, he is liable to suffer frequent injury; this is known as loss of 'protective sensation'. The purpose of this study was to use 3 different methods of sensory testing in order to define high risk groups, that is patients who have lost protective sensation, between shoe wearing and nonshoe wearing groups of the population.

Several studies have compared the sensitivity of vibratometry, Semmes-Weinstein filaments, $265 \mathrm{~Hz}$ tuning fork, biothesiometer, light touch, pin-prick and 2-point discrimination. Vibratometry and the Semmes-Weinstein filaments have been found to be the most effective methods of measuring sensory deficit in the hand and foot. ${ }^{4-6}$ This study therefore uses vibratometry and monofilaments in conjunction with the standard WHO pencil stimulus. The WHO test is a commonly-used method in the Third World and the 1970 WHO expert committee on leprosy states 'the failure to localise firm touch is a useful sign that the patient is now in danger from mechanical injury and burns'. ${ }^{7}$ The graded pressure sensitive monofilaments were based on the Semmes-Weinstein filaments, ${ }^{8}$ a method of proven value in mild nerve damage ${ }^{9}$ which is used in the USA. There are reports of their use in the Third World, ${ }^{4,9}$ but they are not routinely used on patients. Finally the biothesiometer, an electrical vibration meter which quantifies vibration sensation, is only of experimental use in leprosy, although it is widely used in diabetes.

The idea of this study came from the work done by Hammond \& Klenerman, ${ }^{4}$ in which they assessed protective sensation in the foot using Semmes-Weinstein filaments and a biothesiometer. They noted that the average values for their controls and the level of protective sensation calculated with the Semmes-Weinstein monofilaments did not differ significantly from the results of Birke \& $\mathrm{Sims}^{3}$ despite the fact that most of Hammond \& Klenerman's controls were accustomed to barefoot walking. The aim of this study was to use 3 similar methods of testing within 1 distinct of East Africa, but to differentiate between the shoe and nonshoe wearing members of this population, the idea being that if there is a different level of protective sensation within these 2 groups, then knowledge of this difference would improve the practical value of sensory testing.

\section{Method}

\section{PATIENTS AND MATERIALS}

The leprosy patients used in this study were a mixture of inhabitants of Kindwitwi Leprosy Village and those being treated in the surrounding Rufiji delta by the village outreach programme. These were divided into 2 groups: those who once had, or were suffering from plantar ulcers and those who had never suffered plantar ulceration. A history of ulceration was determined by physical examination, medical records and patient interviews. We excluded anyone uncertain as to whether they had suffered plantar ulceration, known diabetic mellitus sufferers, and anyone with any other skin disease or foot pathology. A control group was drawn up, matched for age and sex, using noninfected individuals from Kindwitwi.

Each of these 3 groups was then subdivided into those who wore shoes and those who never had. In order to qualify as a 'shoe-wearer', the individual must have worn shoes continually at least 5 years bef ore they were diagnosed as having leprosy, or in the case of the controls, for at least 5 years. 
The materials used were a ball-point pen for the WHO standard sensory test; a set of 4 graded pressure-sensitive filaments calibrated to bend slightly when forces of $0.5 \mathrm{~g}, 2 \mathrm{~g}, 5 \mathrm{~g}$ and $10 \mathrm{~g}$, respectively, were applied, mounted on wire handles; ${ }^{8}$ and a battery-run biothesiometer with a fixed frequency of $120 \mathrm{~Hz}$ and an amplitude range of $0-25$ micrometres.

\section{General considerations}

To minimize any fear on the part of the patient, no session lasted for more than 20 minutes, so concentration was maintained throughout. The history and examination were carried out in a quiet room with a local doctor as an interpreter. When the patient was comfortable, a brief history was taken detailing age, sex, disease type, duration, treatment, history of past and present ulceration, and history of footwear. We also ensured that the patient had no other foot problems unrelated to leprosy. The examination was then begun. We demonstrated the tests to the patient, and when the subject was certain he or she understood them, the patient was blindfolded and the tests carried out in succession- 4 sites on the sole of the foot were selected; the plantar surface of the big toe, and the first, third and fifth metatarsal heads. These were chosen because they are the commonest sites of ulceration. ${ }^{3}$

\section{Testing methods}

WHO STANDARD SENSORY TEST

This was described by the WHO expert committee on leprosy in their 4th report in $1970 .^{7}$ To test for insensitivity the examiner uses a point of a pen or pencil. The pressure applied is firm enough to dimple the skin but not enough to move feet or toes; the foot must be supported during testing. The blindfolded patient must point to the place where he or she has been touched. A 'positive' WHO test is the ability to point accurately (within $2 \mathrm{~cm}$ ) to the point of dimpling in all 4 positions, a 'negative' test is the inability to do so in 1 or more positions.

\section{GRADED PRESSURE SENSITIVE MONOFILAMENTS}

The filaments were applied in ascending order perpendicular to the skin at an approximate rate of $1 \mathrm{sec}$ touch, $1 \mathrm{sec}$ hold and $1 \mathrm{sec}$ lift, the force being sufficient to bend the thread slightly. The patient then touches the point where the thread had been felt, not having been informed of the moment when the stimulus was delivered; $1-3$ individual stimuli were delivered in each, enough for the tester to be confident that the thread had been felt or not. It is best to test the sites in random order, each area being touched once at a time, returning later to a site if there was doubt the first time. A single site should not be touched several times in quick succession. ${ }^{8}$ The threshold at each site was taken as that filament at which the subject could accurately and reproducibly detect the site of pressure stimulus. The highest threshold from the sites was taken as the 'foot threshold'. If the 10-g filament was not detected at any site the test was recorded as negative for that foot. 
Table 1. Number of feet examined in each group

\begin{tabular}{lll}
\hline & Shoe wearers & Nonshoe wearers \\
\hline Controls & Group A $(n=36)$ & Group B $(n=36)$ \\
With leprosy but no ulcers & Group C $(n=36)$ & Group D $(n=32)$ \\
With leprosy and ulcers & Group E $(n=36)$ & Group F $(n=40)$ \\
\hline
\end{tabular}

\section{BIOTHESIOMETER}

The probe was held lightly on each site and the amplitude of vibration gradually increased from zero until the individual first noticed the sensation. This was repeated 3 times at each site and the mean calculated. The 'foot amplitude' was taken as the mean of the 4 sites, with those subjects unable to feel maximum vibration being given an arbitrary value of 25 micrometers (the maximum amplitude).

\section{Results}

The number of patients involved in each group are shown in Table 1.

\section{BIOTHESIOMETER}

Figure 1 demonstrates that in the shoe-wearing population, if the biothesiometer is used with a threshold value of $4 \mathrm{mV}$, leprosy can be indicated, and the results suggest that if it was used as a screening test it would be very effective and efficient, producing no false positives and only approximately $2 \cdot 5 \%$ false negatives (Table 2 ).

In the nonshoe wearing population, Figure 2 demonstrates that if this same threshold value of $4 \mathrm{mV}$ was used there would be a very high false positive rate of almost $14 \%$, but if the value of $5 \mathrm{mV}$ was used there would be no false positives and only approximately $2 \%$ false negatives.

In trying to find a protective sensation level the results again show a difference between the shoe and nonshoe wearing populations. In the nonshoe wearing population there is a protective level of $14 \mathrm{mV}$ with $94 \%$ of leprosy patients without ulcers being able to feel it

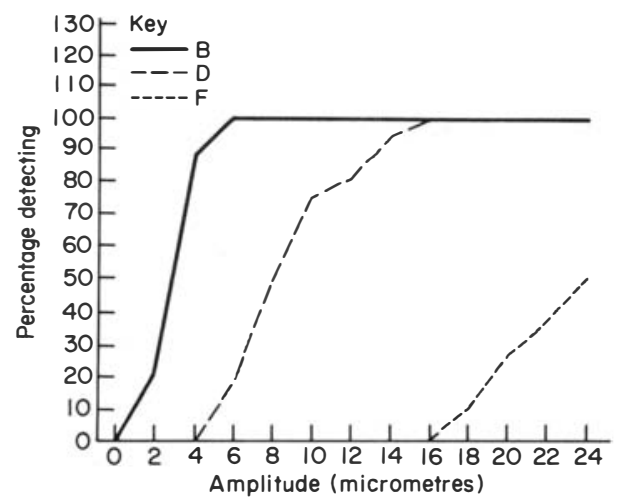

Figure 1. Vibratory sensory thresholds in the shoe wearing groups. 
Table 2. Number of feet in each group responding to particular vibratory levels

\begin{tabular}{lcc}
\hline & \multicolumn{2}{c}{ Biothesiometer reading (micrometres) } \\
\cline { 2 - 3 } Group classification & Felt 4 or below & Felt 5 or below \\
\hline A & 36 & 36 \\
C and E & 2 & 11 \\
B & 31 & 36 \\
D and F & 0 & 2 \\
\hline
\end{tabular}

and $100 \%$ of patients with ulcers being unable to feel it (Table 3). In the shoe wearing population the value of $10 \mathrm{mV}$ was found to be a cut-off for the majority of patients with $83 \%$ of patients without ulcers being able to feel it and $14 \%$ of patients with ulcers being able to feel it (Table 4).

\section{GRADED PRESSURE SENSITIVE MONOFILAMENTS}

In the shoe wearing population the $0.5 \mathrm{~g}$ monofilament could be used as an effective screening test, with a combined false positive and false negative rate of only $6.9 \%$. It would, however, be unreasonable to use this monofilament value on the bare footed population as the combined false positive, false negative rate would be over $37.5 \%$, which is clearly impractical. However, the $2 \mathrm{~g}$ monofilament would not be effective either as too many people would be missed, and so it would appear that for the bare footed population a monofilament value between 0.5 and $2 \mathrm{~g}$ is needed.

This test does not demonstrate any clear protective sensation levels in either of the population groups studied, probably because of its limited sensitivity.

\section{WHO STANDARD SENSORY TEST}

The WHO test failed to demonstrate a ny clear values for either a threshold for leprosy or a protective sensation level. This demonstrates the limitations of having a simple positive/

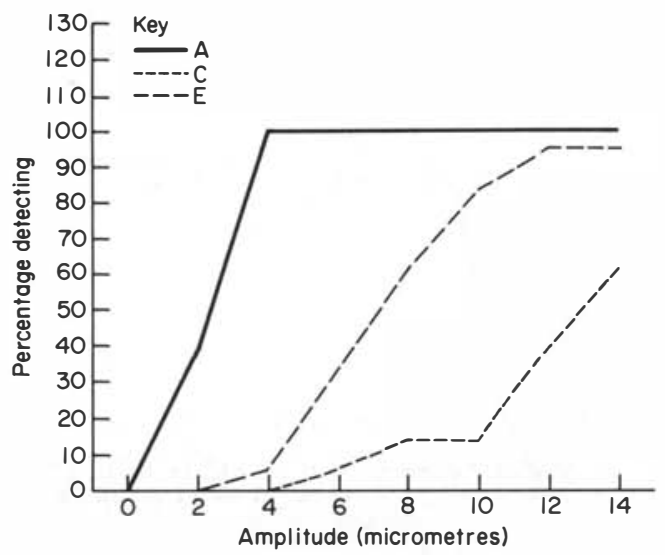

Figure 2. Vibratory sensory thresholds in the nonshoe wearing groups. 
Table 3. Protective sensation level for nonshoe wearing population

\begin{tabular}{lcc}
\hline Group & Felt 14 or below & Felt 21 or below \\
\hline D & 30 & 32 \\
F & 0 & 18 \\
\hline
\end{tabular}

Table 4. Protective sensation level for shoe wearing population

\begin{tabular}{lc}
\hline Group & Felt 10 or below \\
\hline $\mathrm{C}(n=36)$ & 30 \\
$\mathrm{E}(n=36)$ & 5 \\
\hline
\end{tabular}

Table 5. Number of feet in each group responding to each monofialment

\begin{tabular}{lcccc}
\hline Group & Felt $(0 \cdot 5 \mathrm{~g})$ & Felt $(2 \mathrm{~g})$ & Felt $(5 \mathrm{~g})$ & Felt $(10 \mathrm{~g})$ \\
\hline A & 36 & 36 & 36 & 36 \\
B & 24 & 36 & 36 & 36 \\
C & 4 & 21 & 33 & 36 \\
D & 3 & 14 & 21 & 25 \\
E & 1 & 12 & 12 & 20 \\
F & 0 & 3 & 4 & 10 \\
\hline
\end{tabular}

Table 6. Responses of each group to the WHO test

\begin{tabular}{lcc}
\hline Group & $\begin{array}{c}\text { WHO test } \\
\text { positive (\%) }\end{array}$ & $\begin{array}{c}\text { WHO test } \\
\text { negative (\%) }\end{array}$ \\
\hline A & 100 & 0 \\
B & 100 & 0 \\
C & 97 & 3 \\
D & 94 & 6 \\
E & 56 & 44 \\
F & 55 & 45 \\
\hline
\end{tabular}

negative test in comparison to a graded response, and the former is clearly not sensitive enough for this form of testing.

\section{Discussion}

In this study we have compared the use of the 3 methods of sensory testing in the shoe wearing and nonshoe wearing populations. We found that although the WHO test is very simple, cheap and quick, because it is not graded in any way its use is very limited, an observation that has already been demonstrated. ${ }^{4}$

The monofilaments clearly demonstrated differences between the shoe wearing and 
barefoot populations. Due to the limited range and size of the divisions in the monofilaments we used, however, they did not demonstrate specific values that could be used in screening. This we feel could be remedied by using a more finely divided set of monofilaments within the range $(0 \cdot 5-5 \mathrm{~g})$ and also increasing their upper limit.

The biothesiometer, although expensive (costing around $\$ 400^{10}$ ) was by far the most useful test. It demonstrated threshold values and protective sensation values for both groups of patients, the values being different between the groups. The values are all of practical use with sensitivity levels ranging from 70 to $100 \%$ and specificity levels ranging from 83 to $100 \%$.

Leprosy is feared mainly because of the hideous deformities and crippling disabilities that it leads to in some patients. The real goal of leprosy programmes all over the world is to prevent these disabilities and deformities by arresting the spread of leprosy. Disability prevention is one of the major objectives, but although much is being done indirectly by the eradication of leprosy, this is of little help to those who already suffer from this disease. Several reasons have been put forward to explain why disability prevention is not always an integral part of leprosy programmes: it requires individual attention compared to the mass programmes of drug treatment, it is a lifelong commitment because the anaesthesia remains for life despite treatment, specific expertise is required, and disability prevention requires informed and active co-operation between health carers and the patient. ${ }^{11}$

The key in all these factors is time. Time is a very valuable commodity, particularly in the Third World and it is very important that carers use it efficiently. This is achieved (as has been expressed before) by selecting an 'at risk' group of patients on which to direct resources. However, this is only of use if it is done accurately, and it would appear that when studying sensation loss in the feet, grouping all leprosy patients together regardless of footwear is as inaccurate as prescribing a single standard dose of medication to all patients irrespective of their age or sex. This study has demonstrated that threshold values and protective sensation values for sensation loss can be found and used in leprosy patients, but for these values to be effective different values have to be found and used for shoe wearing and nonshoe wearing patients. There is a need for a more detailed study using a larger cohort to be carried out to discover exactly what those values are for each of the various tests used in sensation loss. Our study shows that it may also be necessary to develop some of the tests to increase their sensitivity.

\section{Acknowledgments}

We would like to thank Drs Mbega and Kombo at Kindwitwi Leprosarium, Tanzania for their help in carrying out the project. We would also like to thank Professor K. G. M. M. Alberti for providing us with ideas and equipment.

We are grateful for grants from LEPRA, the St Francis Leprosy Guild and the BMDST.

Our thanks are also due to Professor R. J. W. Rees for helpful comments on the manuscript.

\section{References}

1 Brand P. Insensitive feet. The Leprosy Mission, London, 1966.

2 Lewis S. Reproducibility of sensory testing and voluntary muscle testing in evaluating the treatment of acute neuritis in leprosy patients. Lepr Rev, 1983; 54: 23-30. 
${ }^{3}$ Birke JA, Sims DS. Plantar sensory threshold in the ulcerative foot. Lepr Rev, 1986; 57: 261-267.

${ }^{4}$ Hammond CJ, Klenerman P. Protective sensation in the foot in leprosy. Lepr Rev, 1988; 59: 347-354.

${ }^{5}$ Szabo RM, Dimick MP. Sensibility testing in patients with carpal tunnel syndrome. J Bone Joint Surg (Am), 1984; 66A: 60-64.

${ }^{6}$ Weise MD, Garfin SR, Gelberman RH, Katz MM, Thorne RP. Lower extremity sensibility testing in patients with herniated lumbar intervertebral discs. J Bone Joint Surg (Am), 1985; 67A: 1219-1224.

7 WHO Expert Committee on Leprosy. 4th report. WHO Technical Report Series, 1970, 459.

${ }^{8}$ Pearson JMH. The evaluation of nerve damage in leprosy. Lepr Rev, 1982; 53: 119-130.

${ }^{9}$ Naafs B, Dagne T. Sensory testing; a sensitive method in the follow-up of nerve involvement. Int $J$ Lepr, 1977; 45: 364-368.

${ }^{10}$ Kumar S, Fernando DJS, Veves A, Knowles EA, Young MJ, Boulton AJM. Semmes-Weinstein monofilaments: a simple, effective and inexpensive screening device for identifying diabetic patients at risk of foot ulceration. Diabetes Research and Clinical Practise, 1991; 13: 63-68.

${ }^{11}$ Srinivasan H. Wanted-a planned approach to disability prevention. Indian J Le pr, 1991; 63 (1): 1-4.

Lepr Rev (1994) 65, 58-65

\title{
L'effet des chaussures sur les tests sensoriels dans la lèpre
}

\author{
C. J. Stratford et B. M. Owen
}

Résumé L'objet de cette étude était d'identifier l'effet des chaussures sur les tests sensoriels dans la lèpre. Pour cela nous avons utilisé 3 méthodes d'exploration sensorielle dans un district d'Afrique de l'Est. L'étude portait sur 72 malades lépreux et 36 témoins (malades non lépreux), subdivisés en 2 groupes selon qu'ils portaient habituellement des chaussures ou qu'ils allaient pieds nus. Les méthodes utilisées étaient le test sensoriel de WHO, les filaments calibrés et le biothésiomètre. Les résultats ont révélé des différences significatives entre les seuils dans les 2 groupes de malades avec le biothésiomètre et les monofilaments, démontrant ainsi l'importance d'avoir des valeurs séparées pour le dépistage de la lèpre et pour la détermination des patients les plus à risque de développer un ulcère. L'importance des méthodes quantitatives a été également démontrée, car c'est seulement ainsi que les résultats peuvent être suffisammant standardisés pour identifier les groupes à risque et également, être assez sensibles pour différencier entre les malades portant des chaussures et ceux marchant pieds nus.

\section{El efecto del calzado sobre les pruebas sensorias}

\section{J. Stratford y B. M. Owen}

Resumen El propósito de este estudio es identificar el ef ecto del calzado sobre la s pruebas sensorias del calzado. Esto se logró mediante tresmétodos de pruebas senorias en un distrito de Africa del Este. Incluimos en el estudio 72 pacientes leprosos y 36 pacientes de control (no leprosos) y se dividieron en dos grupos, dependiendo de si normalmente se ponían zapatos o si iban descalzos. Los métodos utilizados fueron la prueba sensoria OMS, monofilamentos graduados y el biotesiómetro. Los resultados indicaron dif erencias significativas de los niveles umbrales entre ambos grupos de pacientes con el biotesiómetro y con los monofilamentos, demostrando la importancia de la exploración para la lepra y evaluando cuáles pacientes tienen más riesgo de desarrollar úlceras. También se demostró la importancia de los métodos de prueba cuantitativos porque solamente entonces se puede normalizar la identificación de los grupos con riesgo para que sea suficientemente sensible para diferenciar entre los pacientes que se ponían zapatos y los que iban descalzos. 